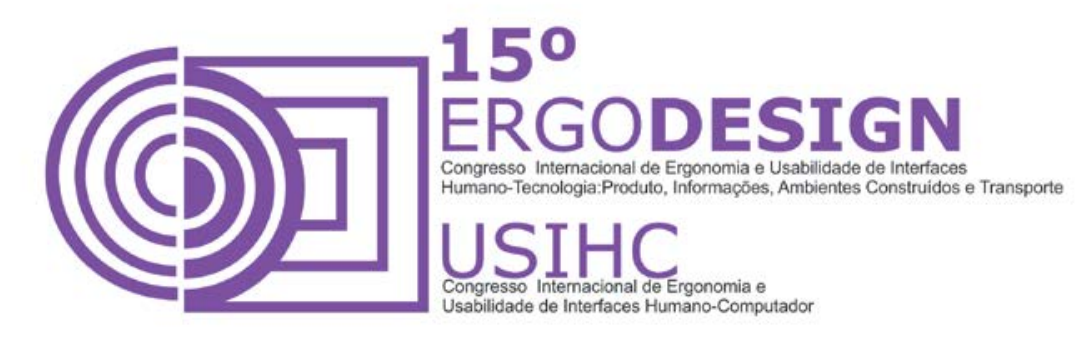

\title{
ASPECTOS ERGONOMICOS E TECNOLÓGICOS NO DESENVOLVIMENTO DE FÔRMAS: UM ESTUDO DE CASO EM JAÚ
}

\section{ERGONOMIC AND TECHNOLOGICAL ASPECTS IN THE DEVELOPMENT OF MOLDS: A CASE STUDY IN JAÚ}

\author{
FAGANELLO, Laís Regina (1); \\ VENTURA, Flávio Cardoso (2) \\ MENEZES, Marizilda dos Santos (3) \\ (1) , FAGANELLO, Laís Regina. UNESP, Esp. \\ e-mail:laisfaganello@hotmail.com \\ (2) VENTURA, Flavio. UNESP, Me. \\ e-mail: flavio.ventura01@fatec.sp.gov.br \\ (3) MENEZES, Marizilda, Dra. \\ e-mail:zilmenes@uol.com.br
}

\begin{abstract}
RESUMO
O desenvolvimento de fôrmas para calçado foi durante os últimos anos um trabalho principalmente mecânico. O presente estudo tem como objetivo apresentar os aspectos relacionados ao desenvolvimento de fôrmas no APL de Jaú, de modo a analisar e comparar as principais evoluções nas empresas entrevistadas nesta cidade. Por meio desta pesquisa qualitativa podem-se analisar os principais problemas que ainda precisam ser melhorados tanto em relação à ergonomia, quanto ao design, conforto, usabilidade aliado a tecnologia e praticidade.
\end{abstract}

Palavras-chave: design, ergonomia, usabilidade, fôrmas, calçados.

\section{ABSTRACT}

The development of molds for footwear was during the last years a mainly mechanical work. This study aims to analyze aspects related to the development of forms in APL Jahú in order to analyze and compare the main developments in the companies interviewed in this city. In this setting can understand the main problems that still need to be improved both in relation to ergonomics, as the design, comfort, usability 


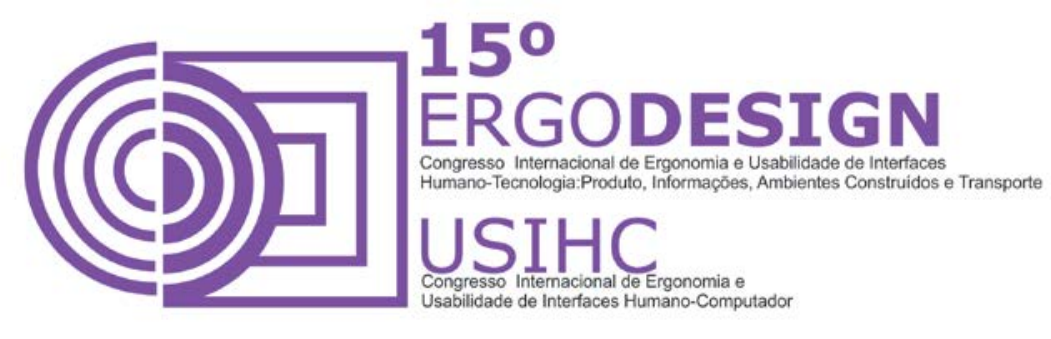

and practicality combined with technology and hereby serve as a parameter for future studies in the area of design and ergonomics.

Keywords: design, ergonomics, usability, molds, shoes.

\section{INTRODUÇÃO}

As fôrmas de um calçado eram feitas de um modo artesanal, o qual evoluiu um pouco esta função, mas as empresas de Jaú, algumas delas ainda utilizam de serviços terceirizados sendo que estes ainda utilizam-se do processo manual na fabricação.

Esta pesquisa faz um levantamento dos principais aspectos do design de fôrmas e seus aspectos históricos, correlacionando sua evolução. Por conseguinte, aborda também o desenvolvimento de fôrmas no APL de Jaú de modo a explicar as partes que são influenciadas pelas fôrmas no design de calçados e explorar a situação local da cidade do estudo de caso.

Por fim, mostra a metodologia qualitativa realizada por entrevistas e apresenta os principais resultados obtidos por meio de um quadro.

\section{ASPECTOS HISTÓRICOS DO DESIGN DE FÔRMAS}

Nos primórdios sabe-se que as pessoas usavam quaisquer materiais de couro de animal ou fibras de vegetais para proteger os pés, presos por tiras. Após a antiguidade os calçados foram se aprimorando, no entanto, durante um longo período da história eles eram iguais tanto na direita quanto na esquerda. Até o final do século XVIII o calçado ainda era fabricado pelo artesão e era feita uma medida exclusiva de fôrma para cada cliente. Após este período, foi feita uma padronização de medidas de diversos clientes baseados na divisão em até 40 vezes do pé do rei Carlos Magno da França. (CARRASCO, 2000).

Ainda comenta Carrasco (2000) que após este procedimento, foi o início da confecção em série, a qual foi substituindo o que era um processo manual, precisamente no século XIX. Esta escalação das fôrmas permitiu que por meio de um mesmo modelo e cor poderiam ser fabricados tamanhos diferentes. Também neste mesmo período histórico, teve a diferenciação da fabricação e comercialização do produto.

No decorrer do século XIX e início do século XX, muitos maquinários foram substituindo a operação manual. O processo da fabricação neste ciclo se tornou independente, de tal modo que é difícil encontrar uma indústria que fabrica sua própria fôrma. Devido a isto, ocorreu uma padronização das formas e também dos pés.

Isto sem mencionar os diversos fatores que influenciam um mesmo número de outra pessoa não encaixar no mesmo tipo de fôrma de um mesmo modelo de sapato. Entre estes fatores seriam: as diferenças étnicas e regionais, a fisiologia da pessoa influencia no formato do pé. Outro fator é o clima, pois o pé incha conforme o calor. Esse fator do clima pode até causar deformações na própria anatomia do pé conforme explica Carrasco, (2000, p. 49): 


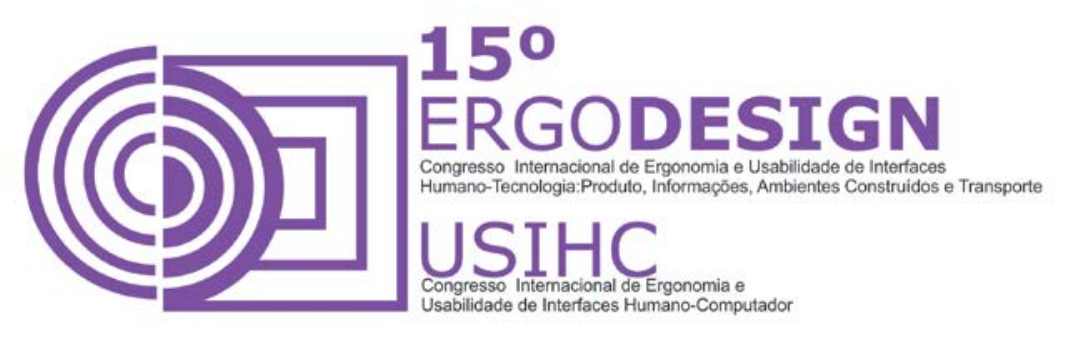

O pé que, com frequência, calça um sapato largo, exercita o aponeurosis dorsal, reforçando-o. Ao contrário, o pé que sofre pressão nas laterais e nos ligamentos dos dedos, ao calçar um sapato de palmilha estreita, recebe a proteção artificial do mesmo. Ao perdê-la, a planta do pé tende a estender-se devido aos ligamentos não estarem suficientemente exercitados para a sua função.

A tecnologia presente na fabricação de fôrmas exige uma precisão e sincronização tanto da fôrma como da palmilha e saltos, sendo que a fôrma é a matriz desse ponto de sincronização. Para Rehfeldt (2011), a maior modificação da fôrma se encontra no bico, tanto em relação à moda quanto ao estilo de calçados. E em relação à parte antropométrica das formas, estas se caracterizam pelos eixos, proporções, altura do salto e elevação do bico. Pode ser também pelo comprimento, perímetro e largura. A medida do pé nunca corresponde a da forma, isto ocorre porque seria inapropriada para a pessoa andar e não teria o quesito estético em sua conformidade.

\subsection{Desenvolvimento de fôrmas em Jaú}

O polo de Jaú atualmente possui 650 estabelecimentos formais, sendo que 150 são empresas fabricantes de calçados feminino. As indústrias mais antigas que ajudaram a Jahú se tornar 0 APL o qual é hoje, a capacidade produtiva do APL é de aproximadamente 130 mil pares por dia. Possui também dois shoppings centers com 180 lojas de calçados. Atualmente, conforme Censo-IBGE (2010) e segundo dados do IBGE (2008), um PIB de mais de 1 bilhão e 500 milhões de reais.

Segundo Pereira et al (2007), a fôrma tem a funcionalidade de adequar o pé ao sapato, podendo ser de madeira ou polímero. Há inúmeros detalhes que devem ser levados em consideração e podem fazer com que a fôrma se adequa ao pé, ou possa causar problemas nos testes. Os principais aspectos seriam a verificação da variedade antropométrica de pés devido a diferenças étnicas, idade, sexo, etc. Diferentes tipos de marchas, volume dos dedos, alteração da forma do pé na marcha, a própria deformação do sapato na marcha, características dos materiais usados na fabricação de calçados sobre a fôrma e até mesmo o solo onde é realizada a marcha.

Também vale citar o próprio espaço, ou seja, o estreitamento da região traseira onde prende o calcanhar, pois se mal dimensionado, o pé tende a empurrar inicialmente para frente e para trás no apoio, ocasionando bolhas. O bico é a parte da fôrma que mais sofre alterações devido à moda e a determinados estilos de calçados, apresentado na Figura 1.

Segundo Vargas (2011) para que uma fôrma realmente seja aprovada para que sempre seja utilizada também devem ser avaliados o ângulo correto para posicionamento de saltos, um dos aspectos mais difíceis no desenvolvimento de fôrmas é fazer com que o salto fique 


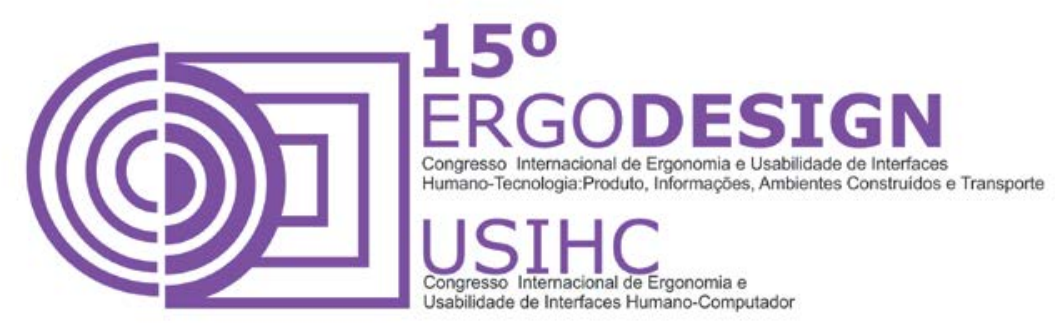

ergonomicamente correto, há os pontos ergonômicos de precisão que precisam ser encaixados na matriz, que faz com que uma medida ínfima errada prejudique o conforto e a eficácia do calçado.

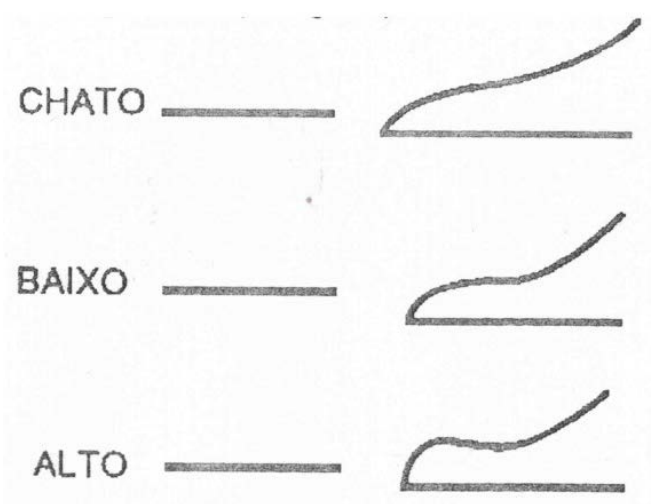

Figura 1: Tipos de bicos

Fonte: Schimidt, 1989

\section{METODOLOGIA}

O trabalho proposto foi desenvolvido a partir de entrevistas semiestruturadas em 4 empresas de Jaú e 2 instituições de ensino da mesma cidade, tratando-se de uma pesquisa qualitativa. As instituições de ensino foram SENAI - Serviço Nacional de Aprendizagem Industrial e Faculdade de Tecnologia de Jahu - FATEC JAHU, já as empresas pediram para não haver identificação do nome fantasia, apresentam-se a seguir as atividades de cada empresa:

- Fabricante de calçados;

- Ateliê de estilismo;

- Fabricante de fôrmas para calçados;

- Fabricante de saltos para calçados.

As principais questões que nortearam a entrevista foram:

- Como era realizado o desenvolvimento no ano 2000 ?

- Como é realizado o desenvolvimento no ano presente?

- Como é realizado os testes de fôrmas?

- Há problemas em relação a conforto térmico?

- Em relação entre questão estética e ergonomia aplicada no calçado, qual seria o item mais valorizado para seu público consumidor?

- Qual o tipo de salto que seu público prefere?

- Qual o tipo de bico que seu público mais usa? 


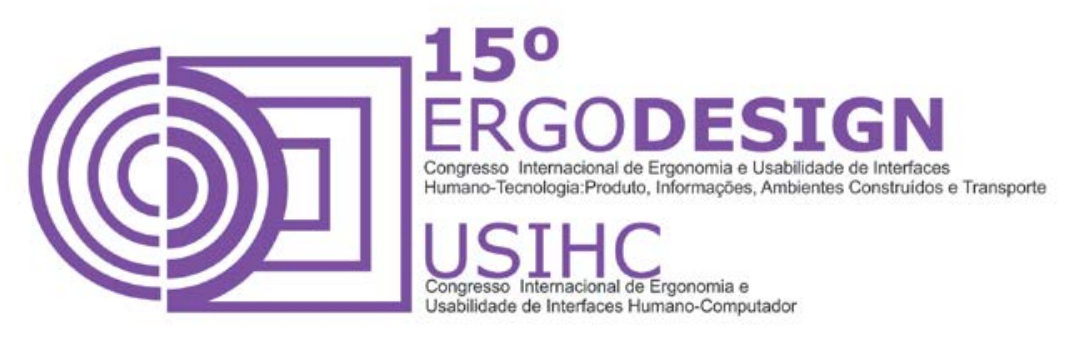

\section{RESULTADOS}

\subsection{Desenvolvimento de fôrmas para calçados femininos}

Primeiramente, apresenta-se um breve descritivo de desenvolvimento de fôrmas para calçados femininos, este depoimento foi realizado pelo fabricante de fôrmas entrevistado nesta pesquisa.

No caso dos calçados femininos, o número inicial, ou seja, número base é o 35, por meio do número 35 são confeccionadas as demais numerações.

O desenvolvimento de uma fôrma pode começar pela palmilha e salto, e também por um calçado pronto. É válido ressaltar que o fabricante de fôrmas desenvolve a nova fôrma a partir de outra pré-existente, geralmente, ele adapta a fôrma pré-existente ao contorno da palmilha, altura de salto e formato do bico ajustando à nova fôrma desejada.

Com relação à altura, geralmente inicia-se o processo com uma fôrma de altura similar, assim evita-se o trabalho de ajuste dos ângulos de inclinação. Após as realizações das alterações da fôrma, um novo calçado deve ser confeccionado para aprovação da nova fôrma, esta avaliação é técnica, sendo que os fatores principais são: conforto; alinhamento do salto e estética.

O calçado desenvolvido deve ser testado em modelos de calce, cada empresa de calçados tem uma ou mais modelos de calçados para a realização dos testes.

Quando a fôrma é aprovada, inicia-se o processo denominado escalamento, ou seja, a partir do número 35 são produzidas fôrmas nos números 33, 34, 36, 37, 38, 39 além de cópias do número base 35 .

\subsection{Fabricação de fôrmas}

As etapas a seguir apresentam os processos de fabricação das fôrmas que sofreram alteração entre o ano 2000 e 2015:

\subsubsection{Etapas de fabricação no ano 2000}

O modelo original era geralmente confeccionado em madeira, apresentado na Figura 2, PEAD (Polietileno de Alta Densidade), ou alumínio.

Esta fôrma original $n^{0} 35$ era acoplada em um torno copiador, apresentado na Figura 3, este equipamento pode alterar as dimensões da cópia da fôrma, tanto no comprimento, como na circunferência, sendo $6,66 \mathrm{~mm}$ e $5 \mathrm{~mm}$ respectivamente, esses são os valores alterados a cada número, tanto para cima, quanto para baixo. 

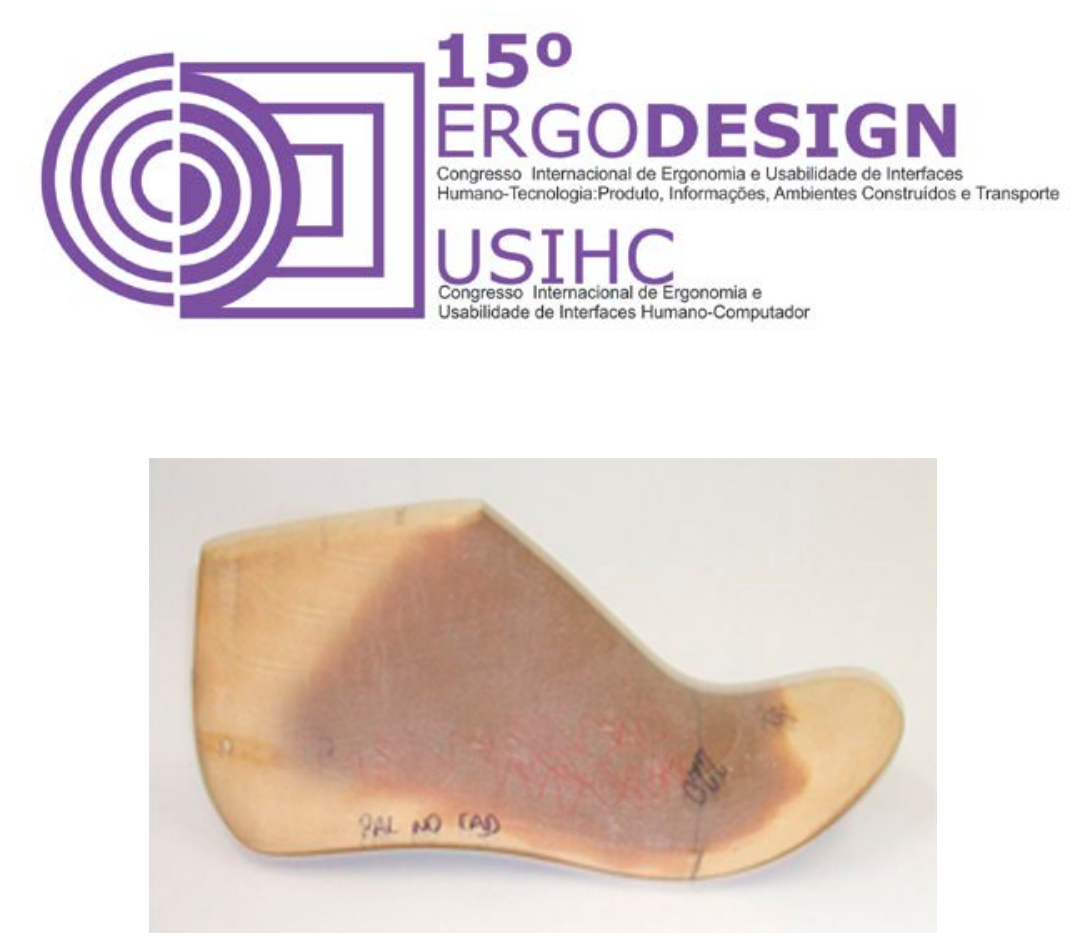

Figura 2: Fôrma original em madeira Fonte: Os Autores (2015)

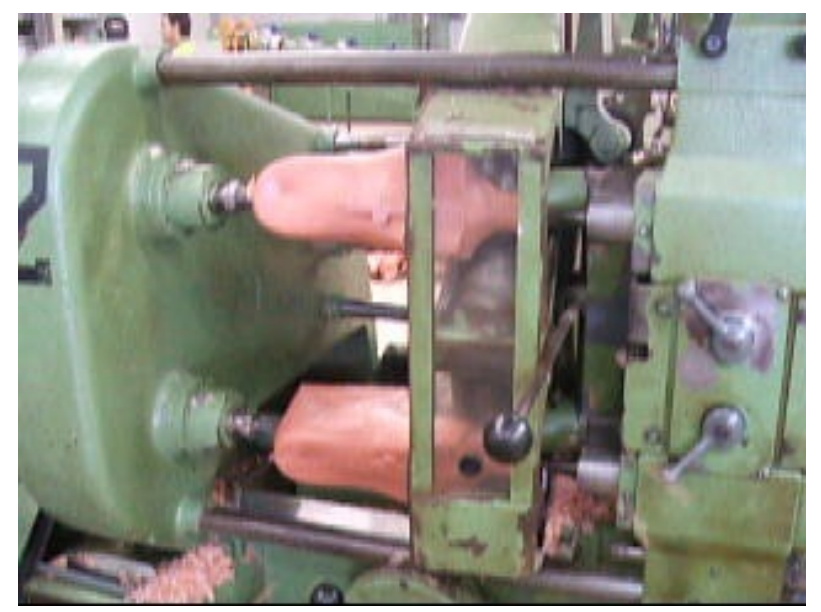

Figura 3: Pré-torneamento

Fonte: Os Autores (2015)

Após o torneamento era realizado, manualmente, o ajuste do bico da fôrma, apresentada na figura 6, por meio de guias e gabaritos. 

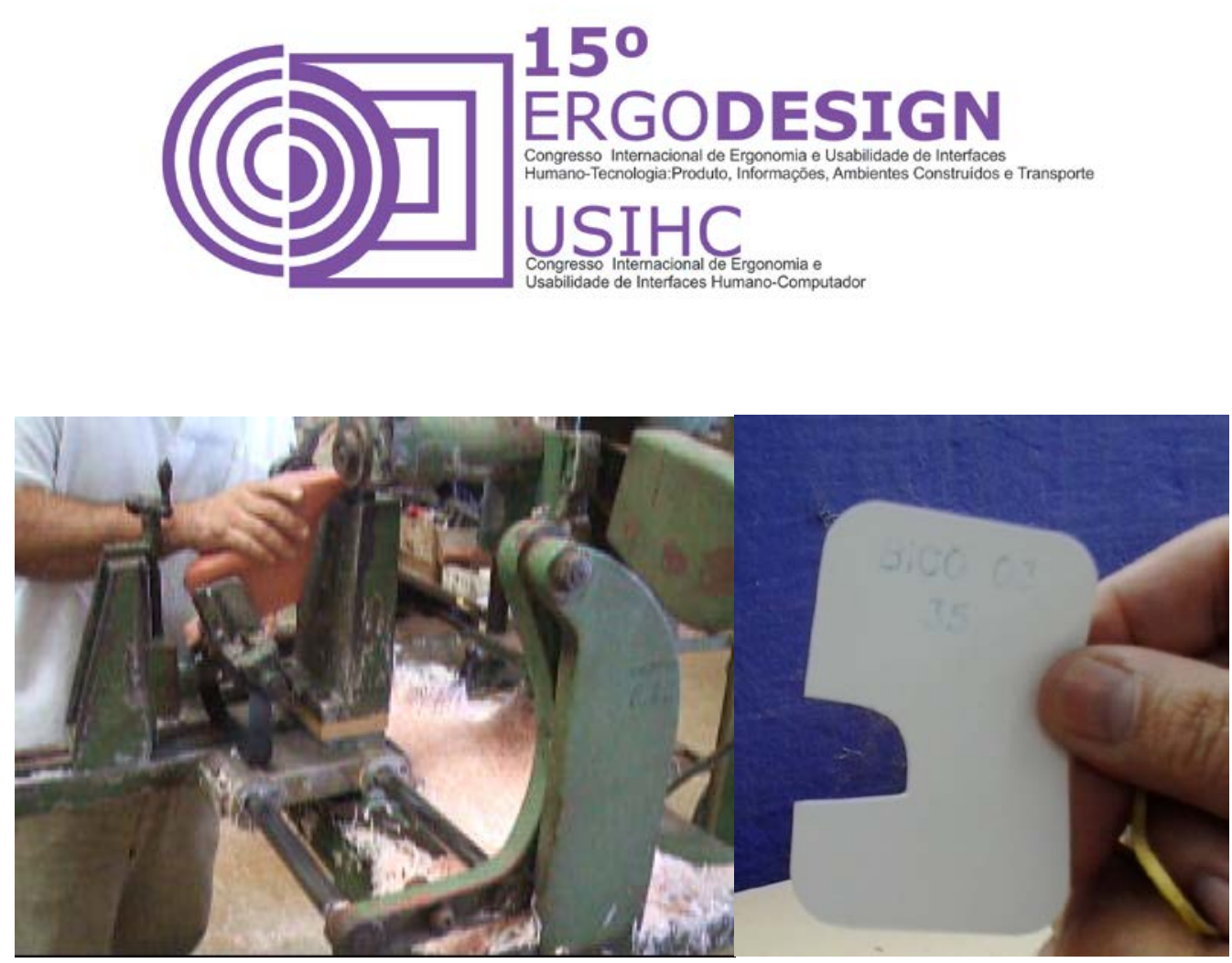

Figura 4: Ajuste do bico da fôrma

Fonte: Os Autores (2015)

Após o ajuste do bico, era realizado, manualmente, o ajuste da região traseira da fôrma apresentada na figura 7, por meio de guias e gabaritos.

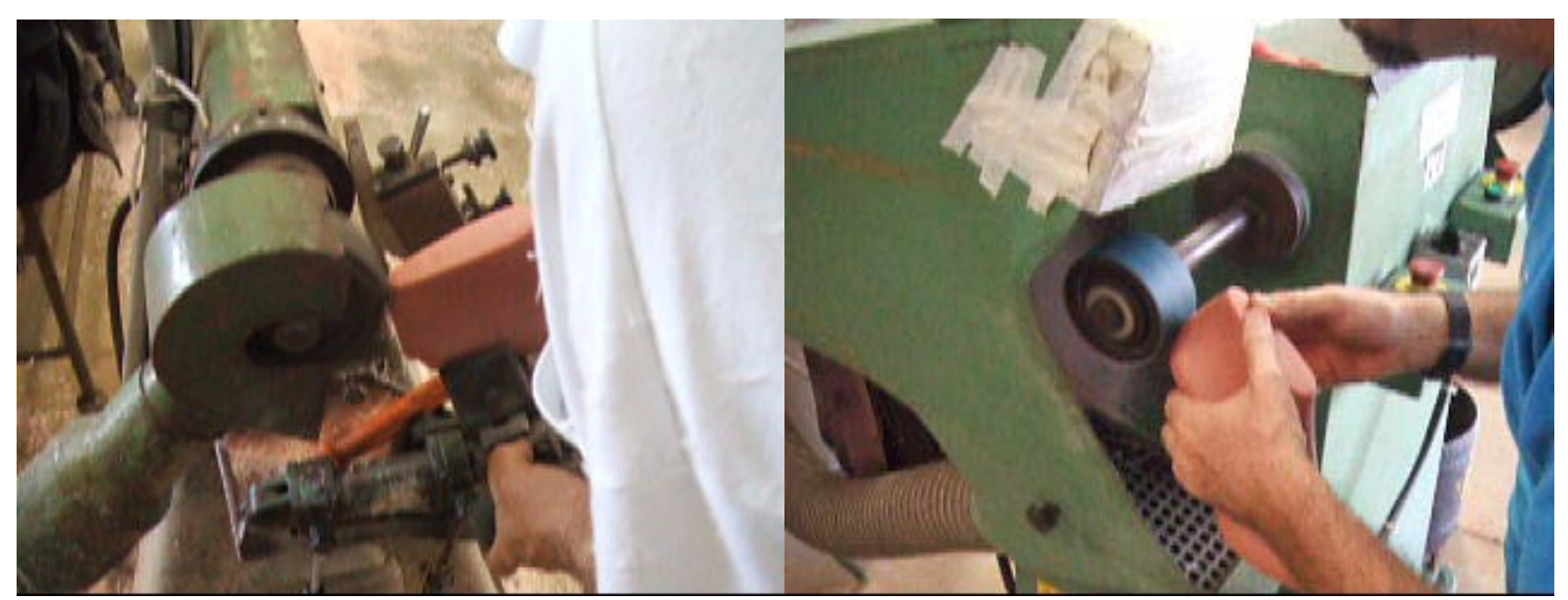

Figura 5: Realização do ajuste do calcanhar

Fonte: Os Autores (2015) 


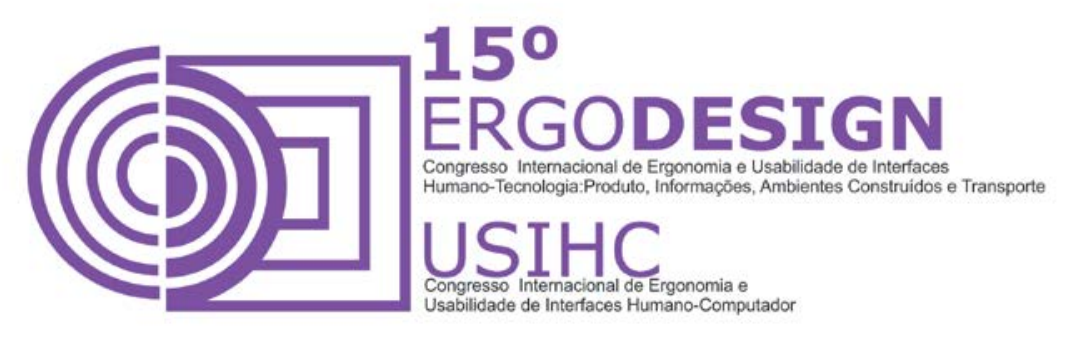

Atualmente, o modelo original é em PEAD, porém é copiado em um digitalizador 3D, apresentado na Figura X.

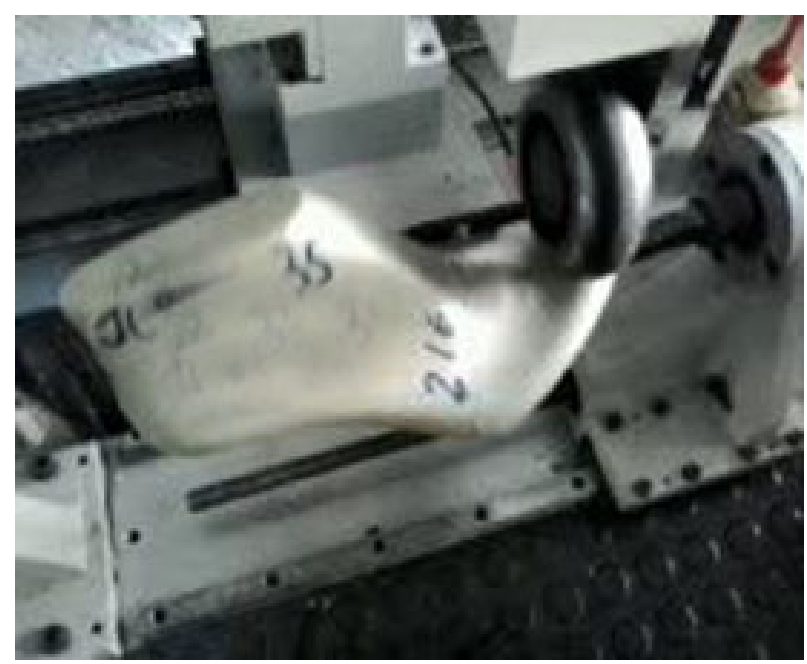

Figura 6: Digitalização da fôrma original

Fonte: Os Autores (2015)

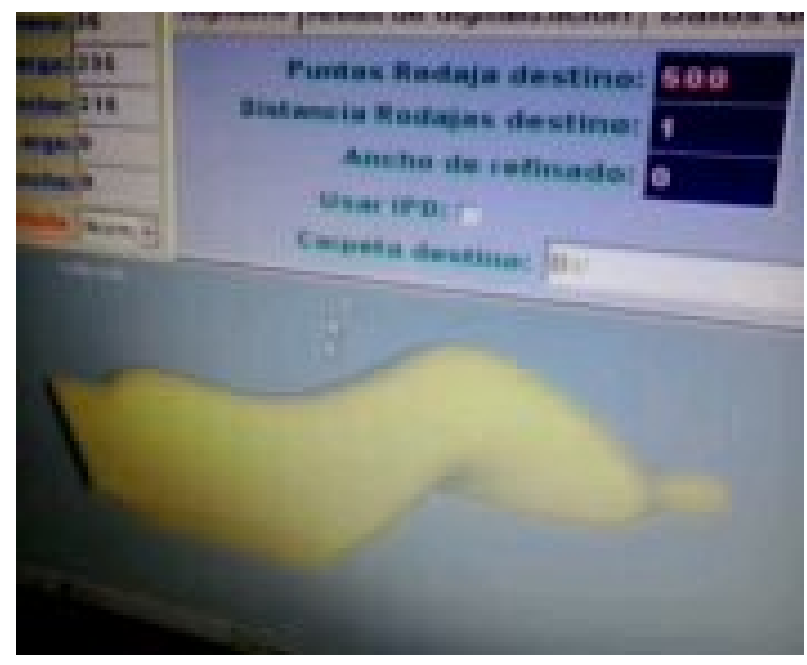

Figura 7: Fôrma digitalizada

Fonte: Os Autores (2015) 


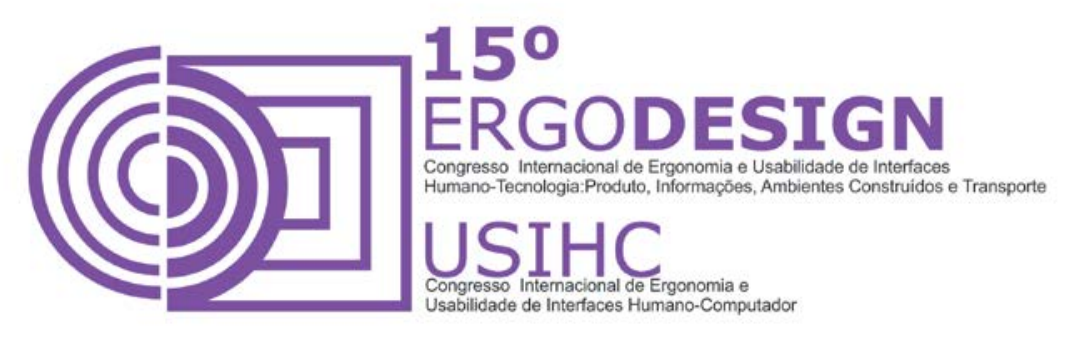

Posteriormente à digitalização, o processo de torneamento, e os demais processos são todos via CAD/CAM, inclusive ajuste do bico e do traseiro, sem contato manual, reduzindo-se a margem de erro e o tempo de fabricação, segundo o fabricante de fôrmas.

É possível até realizar o desenvolvimento do modelo original $\mathrm{n}^{\circ} 35$ diretamente a partir do computador, como apresenta a figura 8, pode-se alterar bico, ângulos e demais dimensões da fôrma. Embora esse processo ainda não seja realizado no APL estudado. Porque eles preferem ter uma forma já aprovada e fazer em cima dela.

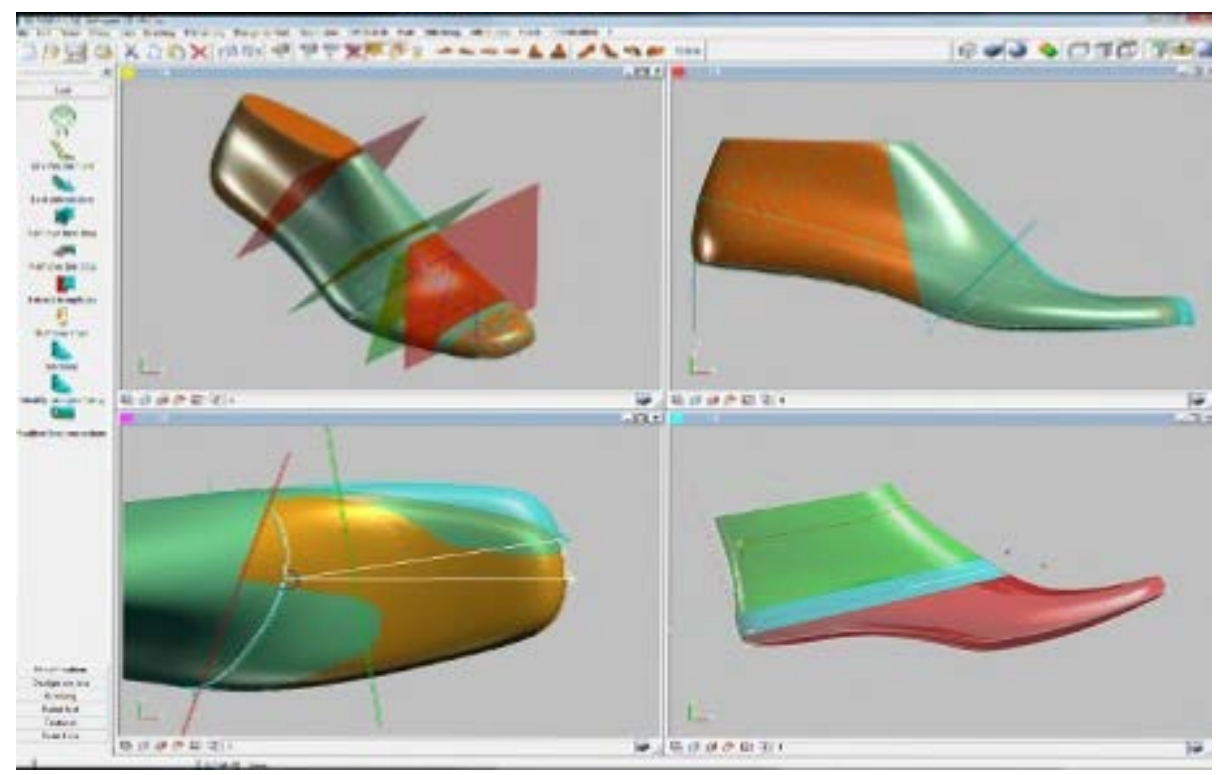

Figura 8: Tecnologia Cad

Fonte: <http://www.romans-cad.com/?page_id=8679\&lang=pt-br>

\subsection{Análise das entrevistas}

\subsubsection{Aprovação da fôrma}

Em relação à aprovação da fôrma, na maioria das empresas é feito um teste momentâneo, onde primeiramente, a modelo de calce $\left(n^{\circ} 35\right)$ permanece sentada, posteriormente, fica em pé e realiza uma caminhada rápida. Apenas uma das empresas entrevistadas aplica um teste de uso por uma semana com a modelo de calce. Esse teste é feito em caso de vendas em grande quantidade.

Após a realização dos testes, a modelo pode especificar o local onde há desconforto. São realizados possíveis ajustes, é feito um novo par de calçado. Por fim, após aprovação encerrase este ciclo com a escala e produção desta fôrma. Segundo a empresa entrevistada, o ideal é 


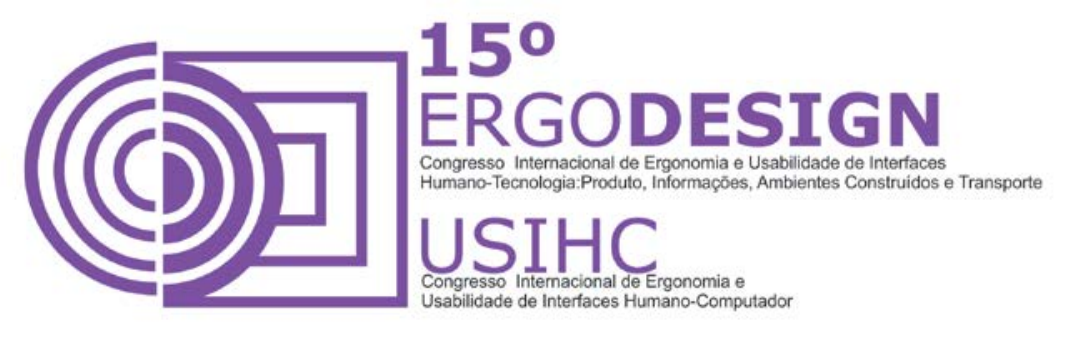

fazer este teste de uso por uma semana em todas as fôrmas, mas por falta de tempo isto não é realizado.

\subsubsection{A ergonomia e os materiais do calçado}

Em relação ao conforto térmico, a entrevistada já apresentou problemas, porém mais relacionado ao material usado em rasteiras e sapatilhas, onde o material laminado se desgastava mais quando as pessoas que tinham mais liberação de ácido úrico utilizavam o produto, neste caso, a empresa fabricante indicou com uma etiqueta que o produto laminado era sensível e desgastava-se mais. $E$ em relação à necessidade de ter um material que ajudasse na transpiração dos pés, problema muito comum em sapatilhas e sapatos fechados, a empresária informou que sabe desta dificuldade dos consumidores e que os fornecedores já tentaram desenvolver um material derivado de papel para os solados, porém não deu certo e ainda não conseguiram desenvolver um material adequado que solucionasse o problema.

A substituição ao longo dos tempos dos materiais sintéticos dos tipos mais rígidos pelos mais macios teve uma ligação ao fator tecnológico e também relacionado ao conforto. O couro teve uma escassez devido ao preço, procuram-se muitos materiais alternativos, mas que tenham um aspecto mais de maciez.

\subsubsection{A ergonomia e o visual do calçado}

Sobre a relação entre estética e ergonomia para o consumidor, e consequentemente para a empresa no momento de compra ou aprovação de um calçado, duas empresas informaram que para seu público era o item estético o aspecto mais importante e outras duas informaram que era o calce, ou seja, o conforto ergonômico.

Em relação aos saltos, pode-se averiguar que em média a maioria das empresas preferem saltos médios, de modo que as que preferem saltos baixos ou altos dependem muito do público que a restringem, um exemplo é o salto baixo, onde há um público senhoril que já compra este tipo de calçado, e estas consumidoras não fazem questão de usar um produto que esteja na moda como, por exemplo, um salto mais alto. O outro exemplo é o inverso, um público que prefere sentir desconforto, mas estar aparentemente com um visual mais belo com um salto mais alto e mais fino.

Nas empresas entrevistadas desenvolvem-se saltos grossos, finos, médios, e também altos e baixos, enfim, são confeccionados todos os tipos de saltos, porem as empresas destacaram a fabricação de saltos grossos.

Com relação aos bicos dos calçados, segundo os entrevistados, antigamente, principalmente os calçados tipo bico fino causavam problemas relacionados a joanetes, no momento, a indústria ampliou as opções para bicos redondos e quadrados, embora os finos ainda sejam tendência forte.

Outra questão importante é a observação de uma empresária sobre o perfil das usuárias de saltos, sendo que as adeptas dos saltos mais altos eram as mais jovens até uma faixa etária 


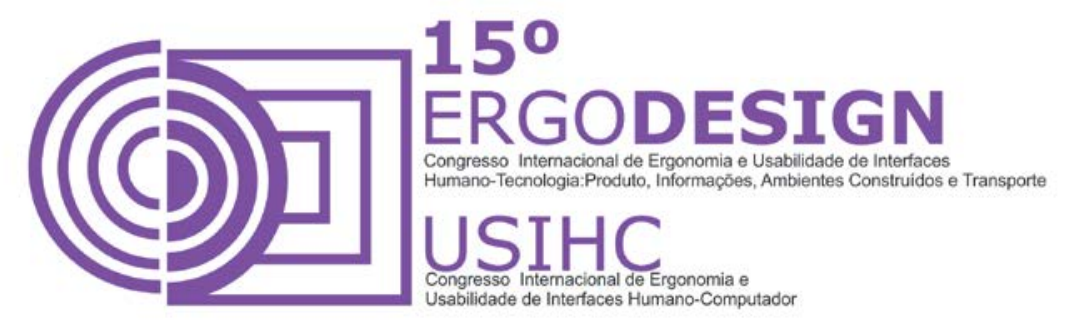

dos 25 anos, e até os 25 anos, adeptas de saltos médios e altos, passando a ser somente médios e baixos após os 35 anos, devido ao fato de que a mulher está cansada de usar salto alto todos os dias no trabalho, principalmente em dias quentes, onde o pé incha e ocasiona desconforto. Esta constatação foi representativa por ser observada pelas respostas de outros entrevistados ao longo da pesquisa.

Os principais resultados obtidos são apresentados no quadro a seguir:

Quadro 1 - Principais resultados obtidos

\begin{tabular}{|c|c|c|}
\hline & $\mathbf{2 0 0 0}$ & $\mathbf{2 0 1 5}$ \\
\hline Fôrmas & Fabricação mecânica & Fabricação automatizada \\
\hline Sintéticos e Couros & mais rígidos & mais macios \\
\hline Saltos & altos e finos & $\begin{array}{c}\text { Todos os tipos de saltos, } \\
\text { destacando-se os médios e } \\
\text { grossos }\end{array}$ \\
\hline Bicos & finos & $\begin{array}{c}\text { Todos os tipos de bicos, } \\
\text { destacando-se os quadrados } \\
\text { e redondos }\end{array}$ \\
\hline
\end{tabular}

Fonte: Autores (2015)

\section{CONSIDERAÇÕES FINAIS}

Os pés possuem diferenças antropométricas, étnicas, fisiológicas e até mesmo diferenças do arco plantar em posicionamento durante a marcha, até mesmo fatores externos como clima, o calor, por exemplo, onde o pé pode aumentar o seu dimensionamento e inchar. São muito detalhes e fatores que podem alterar na aprovação da forma. Diante disto, ainda é um desafio para as empresas acertar a fôrma para seu respectivo usuário.

A tecnologia facilitou muito a questão de transporte, pois antes alguns serviços relacionados a fabricação de formas ainda era feito em outras cidade e demorava muito para ficar pronto. Hoje não, diminuiu o tempo de fabricação e melhorou no sentido de precisão de medidas, embora nem todas as empresas se beneficiem das mesmas ou todas as tecnologias. Talvez, conforme um empresário entrevistado nesta pesquisa afirmou um dos caminhos a seguir é experimentar a fôrma, realizar mais testes e seguir o que já tem dado certo.

Um importante aspecto a ser considerado é que a fabricação mecânica começou a se tornar automatizada, de modo que fosse digitalizada e isto facilitou muito tanto para o funcionário 


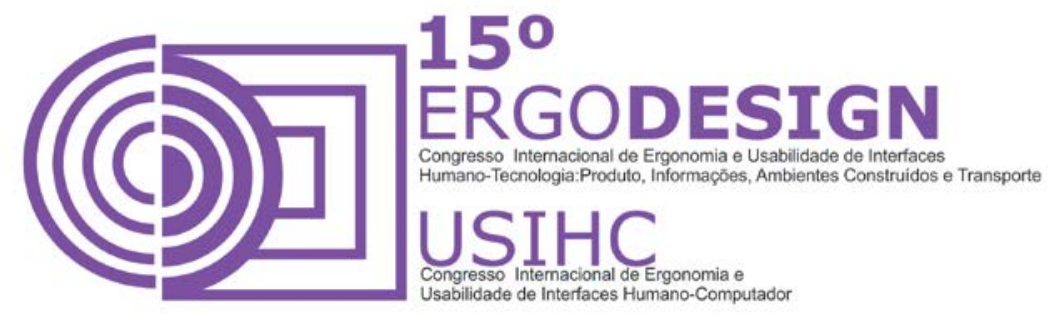

quanto empresário e otimização de tempo. Anteriormente apresentava diferenças com relação ao modelo original e agora pelo sistema Cad Cam essas diferenças não ocorrem porque são feitos com equipamentos de precisão.

\section{REFERÊNCIAS BIBLIOGRÁFICAS}

CARRASCO, José Maria. Estilismo e Modelagem - Técnica do Calçado I. Novo Hamburgo, 2000.

OLIVEIRA, A. M. R. GARCIA, L. B. R. O pólo calçadista de Jau: suas implicações sócio económicas e espaciais.

PEREIRA, M. P. DUARTE, L. S. PASCO, M. R. As limitações das fôrmas de salto alto e o uso de Órteses: Uma abordagem da ergonomía. Encontro Latinoamericano de desenho. Palermo, 2007.

REHFELDT. Uma Heurística aplicada a um problema de escalonamento na industria calçadista. Dissertação de Mestrado. UFRGS, Porto Alegre, 2001. 98 p.

SCHMIDT, Mauri Rubem. Modelagem técnica de calçados. Porto Alegre, SENAI/RS 1989.

VARGAS, India. Paula. Reis. Conforto no calçado feminino. Trabalho de Conclusão de Curso. Florianópolis, UDESC, 2011. 98 p. 